\title{
The Role of an Aligned Curriculum Design in the Achievement of Learning Outcomes
}

\author{
Abdullah A.H. Alfauzan ${ }^{1}$ \\ Nessima Tarchouna ${ }^{2} \bowtie$ \\ Department of Arabic Language and Literature, College of Arabic \& Social Studies, Qassim University, \\ Buraydah, Saudi Arabia \\ Department of English, Faculty of Arts and Humanities, University of Sousse, Tunisia
}

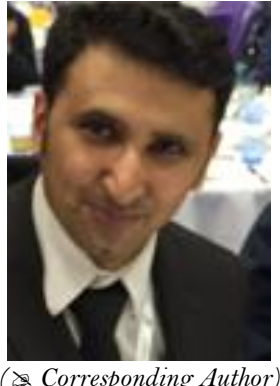

Corresponding Author

\begin{abstract}
The importance of learning outcomes (LOs) as a central component of LOs-based curriculum design has been emphasized by many higher education experts and researchers (Biggs, 1999; Adam, 2006; Kennedy et al., 2006; Biggs and Tang, 2007; Warnier et al., 2010). However, the important role played by program and course curriculum design in securing a successful shift from the intended learning outcomes (ILOs) to the achieved learning outcomes (ALOs) or simply (LOs) still requires further attention. This study highlights the tight relationship between learning outcomes and LOs-based curricula and argues that an appropriately aligned curriculum design can facilitate and optimize the successful achievement of the intended learning outcomes. A practical model of the implementation of Biggs's theory of "Constructive Alignment" (CA) is, also, presented through an application on the course (Theories of Translation) delivered under the code (ENG 371) by the department of English language and translation, Faculty of Arabic Language and Social Studies, Qassim University, KSA. The focus on HE systems in countries which are not part of the European Higher Education Area (EHEA), like KSA, could contribute to a better mapping and evaluation of the effects of the implementation of Bologna reforms outside Europe. This research mainly outlines, John Biggs's constructive alignment method, theoretically, and then, puts to practice its operational model through a practical case study of course curriculum design. The main question this research aspires to answer is: "How to implement the constructive alignment method in a course curriculum design to best support the achievement of learning outcomes?”
\end{abstract}

Keywords: Learning outcomes, Curriculum design, Constructive alignment, Back-design, Backwash.

Citation | Abdullah A.H. Alfauzan; Nessima Tarchouna (2017). The Role of an Aligned Curriculum Design in the Achievement of Learning Outcomes. Journal of Education and e-Learning Research, 4(3): 81-91.

History:

Received: 16 May 2017

Revised: 6 June 2017

Accepted: 19 July 2017

Published: 18 September 2017

Licensed: This work is licensed under a Creative Commons

Attribution 30 License (c)

Publisher:Asian Online Journal Publishing Group
Contribution/Acknowledgement: Both authors contributed to the conception and design of the study.

Funding: This study received no specific financial support.

Competing Interests: The authors declare that they have no conflict of interests.

Transparency: The authors confirm that the manuscript is an honest, accurate, and transparent account of the study was reported; that no vital features of the study have been omitted; and that any discrepancies from the study as planned have been explained.

Ethical: This study follows all ethical practices during writing.

\section{Contents}

1. Introduction 82

2. Methodology

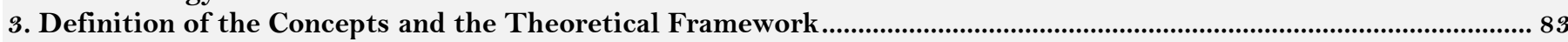

4. Case Study: The Constructive Alignment of the Course 'Theories of Translation'......................................................... 8 8

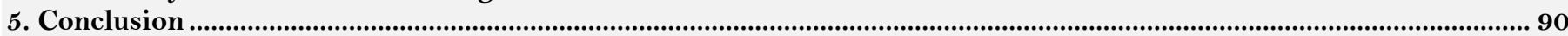

References. 


\section{Introduction}

Out of concern for readability and comparability of diplomas as well as to encourage student mobility ${ }^{1}$ and secure and enhance quality, higher education reforms across the world have set the adoption of the learning outcome-based approach as one of their objectives. As a consequence, in many countries, new approaches to curriculum design have been used to match the new concern with the achieved results of the teaching/learning experience.

Within this context, KSA is no exception as higher education reforms are being implemented at national and local levels. Qassim University, for example, has been revising, re-designing and newly implementing curricula for the purpose of quality assurance and enhancement and to increase the competitiveness of the qualifications it has been delivering so far. To achieve this end, the different institutions at Qassim University have shifted to the learning outcomes-based approach in teaching and curriculum design.

The LOs-based approach to learning locates the learning outcomes at the heart of the pedagogical project: (LOs) are the basis of the learning experience (in the meaning of starting point) and here they are referred to as intended learning outcomes (ILOs) ${ }^{2}$ and the end result or achieved learning outcomes (ALOs) or simply (LOs). And this is where curriculum design plays an important role: it is expected to provide an operational map to guide the different partners involved in the teaching/learning experience. A good curriculum design is expected to embed a functional methodology which, once put to practice, will facilitate the shift from the intended learning outcomes (ILOs) to the achieved learning outcomes (LOs). This study contends that Biggs's constructive model of curriculum design can bring an important contribution in this area.

Addressing the importance of curriculum design in the achievement of learning outcomes, this study attempts to answer the following question: How can Biggs's model of constructive alignment be implemented to facilitate the achievement of the intended learning outcomes and maximize the students' chances to reach the expected results or (LOs)?

To this effect, this piece of research argues for the necessity of adopting a curriculum- design model based on "constructive alignment" (Biggs and Tang, 2007) as recommended by the National Qualification Framework $(\mathrm{NQF})$ for $\mathrm{HE}$ in KSA, and clearly stated in the course specification template ${ }^{3}$ issued by the National Commission for Academic Accreditation and Assessment (NCAAA). The NQF refers to alignment in terms of 'appropriateness': " Programme and course specifications should include methods of teaching and student activities that are appropriate for the learning outcomes in each of the domains". Appropriateness is also required in the case of the assessment tasks: "Tests, examinations and other required assessment tasks should include appropriate forms of assessment of learning in each of the domains" (National Qualifications Framework for HE in KSA, 2009).

The course specification template (CS) issued by the National Commission for Academic Accreditation and Assessment in KSA (NCAAA) explicitly mentions the alignment of the different components and highlights the concept of 'alignment' in the rubric "Course Learning Outcomes in NQF Domains of Learning and Alignment with Assessment Methods and Teaching Strategy” (Course Specification (C S), 2015).

This study proceeds from the conviction that if we adopt a holistic systemic vision to curriculum design and, proactively, embed at the level of its structure the preconditions for the success of its different components in their interrelation, we can maximize the effectiveness of curriculum design. The latter will become one of the essential facilitators in the achievement of the intended learning outcomes. To this end, the study makes use of John Biggs's 'constructive alignment model' (Biggs, 1996;1999;2003a) to put to practice its proactive dimension (as a model which anticipates the solution of possible gaps and mismatches in the learning experience) and its operational method which can contribute to (ILOs) achievement.

\section{Methodology}

The methodology followed in this research relies on descriptive and observational analysis, the purpose of which is "to develop a holistic understanding of the phenomena under study that is as objective and accurate as possible given the limitations of the method" (Dewalt and Dewalt, 2002). The study, also, uses participant observation(data was collected from participants in two workshops related to the issue researched in this study).Informal interviews presented an opportunity to check the degree of awareness teachers/participants in the workshop had about the learning outcomes-based approach and the constructive alignment curriculum design model. The following three simple questions formed the basis of the informal interviews:

- Q1: Are you familiar with the LOs-based approach to learning/teaching?

- Q2: How do you align the assessment tasks with the ILOs of your course?

- Q3: How do you align the teaching/learning activities with the ILOs of your course?

Documentary analysis is also used in this study as a means of referential contextualization of the issue researched. Within this framework reference is made to the NQF for HE in KSA (2009). The course specification (CS) of the course 'Theories of Translation', delivered under the course code (ENG 371 ) by the department of English Language and Translation of the Faculty of Arabic Language and Social Studies, Qassim University KSA, will be referred to in the context of the case study.

This study is structured as follows: two theoretical parts and a practical case study. In the first part, the presentation of definitions of the concepts of 'learning outcomes' and 'curriculum design,' will be an opportunity, for the researchers, to point at the importance of curriculum design in the achievement of (LOs). The second part will introduce John Biggs's model of 'Constructive Alignment' (CA) as an effective approach to curriculum design in the context of the learning outcomes-based approach to learning. The third part will be devoted to the case study. The latter will provide the researchers with an opportunity to identify some of the mismatches which frequently occur at the level of course curricula design (in the English and Translation department). This will be

'See the European Qualification Framework of higher education (EQF).

The National Qualifications Framework for HE in KSA (2009).

${ }^{2}$ This study will use ILOs and Los interchangeably

3 This study refers to the National Qualifications Framework for HE in KSA (2009) 
followed by an attempt to re-design an aligned curriculum for the course 'Theories of Translation' (ENG 371) in the hope of stimulating an aligned re-design of other courses in the department.

\section{Definition of the Concepts and the Theoretical Framework \\ 3.1. Learning Outcomes}

The ECTS Users' Guide (European Credit Transfer System guide) states that 'Learning outcomes describe what a learner is expected to know, understand and be able to do after successful completion of a process of learning."(European Commission Education and Culture DG, 2009). The University of Western Australia (n.d) (Centre for the Advancement of Teaching and Learning) defines learning outcomes as "statements of the attributes and capabilities that a student should be able to display on successful completion of the unit" (Curriculum Development, p.7). From the perspective of the Michigan University Center for Research on Learning and Teaching (CRLT) "learning outcomes and competencies describe specific measurable skills, knowledge or attitudes that learners will have achieved through the education program" (Curriculum Design, p. 1).

Jackson et al. (2003) highlight the difference between learning outcomes (LOs) and intended learning outcomes (ILOs): "a learning outcome is what results from a learning process" while "intended learning outcomes are statements that predict what learners will have gained as a result of learning" (Jackson et al., 2003).

Biggs and Tang (2007) assert that learning outcomes can be defined in relation to three levels:

1) An institutional level.

2) A program level.

3) A course level (Biggs and Tang, 2007).

To the above levels of definition of (LOs), two more levels are, also generally, referred to, following an embedded structure where each level of definition has its own relevance and requires, for overall coherence, to interrelate with the other levels hierarchically. The two other levels of reference, when defining LOs, are: the national level (which requires the reference to the national qualification framework (NQF)) and the international level (which refers to the international qualification frameworks (IQF)), that set the criteria for quality assurance and the norms of recognition of higher education qualifications internationally. The hierarchy of frames of reference which, implicitly or explicitly, interfere in the definition of learning outcomes can be schematized as shown in Figure 1.

\section{International}

\section{National}

\section{Institutional}

\section{Program}

\section{Course}

Figure-1. Levels of Reference of Learning Outcomes.

The above frames of reference outline an embedded structure where each level refers to the upper one and predetermines the lower levels. When defining course learning outcomes (CLOs) for example, the following levels of reference should be taken into consideration (Figure 2).

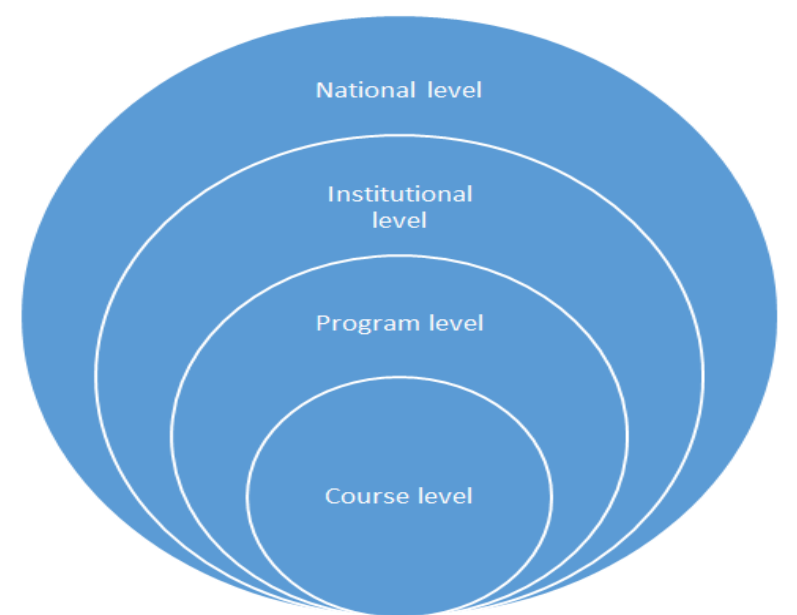

Figure-2. Embedded Structure of Reference for Course Learning Outcomes (CLOs). 
Most definitions of learning outcomes foreground a pedagogical intention and are based on the expected results of a program or course in terms of knowledge, skills, abilities and attitudes. The second important element in the definitions is that learned outcomes have to be demonstrated by students (Biggs, 2003; Maher, 2004; Kennedy et al., 2006; Warnier et al., 2010).

\subsection{Curriculum Design}

The Centre for Excellence in Teaching and Learning (2012) at Camosun college defines curriculum as "principle-driven actions and processes that guide and foster significant learning experiences. It is a planned, thoughtful and deliberate course of actions that ultimately enhance the quality and impact of the learning experience for students" ("Leading Practices in Curriculum", 2012, p. 3). This definition locates the importance of curriculum design in its regulative function as the locus of quality assurance and enhancement. Wiggins and McTighe (2001) focus on the components of curriculum in their relation to curriculum goals. They assert that curriculum moves "beyond mapping out the topics and materials; it specifies the activities and assessments to be used in achieving its goals" (Wiggins and McTighe, 2001). Gaff and Ratcliff (1997) explain that curriculum may be analyzed from many perspectives by focusing on "the purposes, experiences, or outcomes of the curriculum" (Gaff and Ratcliff, 1997). Other definitions highlight the necessity of the alignment of the different elements in the curriculum cycle. In her article "Curriculum Development", Mckimm (2003) explains that "curriculum design is not carried out in isolation, but is part of an iterative planning, development, implementation and review cycle"(Mckimm, 2003). She also argues that the alignment of the implemented curriculum with the designed one is a precondition for the achievement of the learning outcomes: "One of the functions of a curriculum is to provide a template or design which enables learning to take place”(Mckimm, 2003). The Michigan University Center for Research on Learning and Teaching (CRLT) extends the definition of curriculum design to all its constituent components and states that it is "an academic plan which should include: the purpose of the curriculum (i.e. goals for student learning), content sequence (the order of the learning experience), instructional methods, instructional resources, evaluation approaches and how adjustments to the plan will be made based on experience or assessment data"("Curriculum Design", p. 1).

Biggs (2003a) highlights the importance of the systemic and integrated nature of curriculum design as a facilitator of LOs attainment; he argues that "In an integrated system... all aspects of teaching and assessment are tuned to support high level learning. Constructive alignment (CA) is such a system. It is an approach to curriculum design that optimizes the conditions for quality learning" (Biggs, 2003).

\subsection{Constructive Alignment}

\subsubsection{The Theoretical Framework}

Throughout the world, higher education culture has undergone a radical change from a transmission culture, which positions the teacher as the center of knowledge and the student as the passive receiver of the covered content, to a more supportive culture where the student becomes an active partner in the learning experience. This change has been described as "a shift from a traditional 'instructional paradigm' with its focus on teaching and instruction to 'a learning paradigm' that enables students to discover and construct knowledge for themselves" (Maher, 2004). As a consequence, a shift in methods of curriculum design has occurred. The major change is from a content-based and teacher-centered model to a learning- outcomes based type of design and a student-centered approach.

The move to the objectives-based education (OBE) and the LOs-focused approach was first launched as a reaction against traditional methods of teaching and curriculum design. And it is within this innovative frame that John Biggs's constructive alignment method was first developed as a new curriculum design model which aims at optimizing the students' chances for the attainment of the learning outcomes (Biggs, 1996;1999).

In the context of the LOs-based approach, the literature on curriculum design has given a great importance to constructive alignment. The systemic and integrative nature of the LOs-based model of curriculum design does require the constructive alignment of all the components of the system. Indeed, "the outcomes model is predicated on a teaching and learning system that is aligned" (Jackson et al., 2003). Alignment is set as a precondition for quality assurance in curriculum design by the European Centre for the Development of Vocational Training (CEDEFOP): "proper alignment of intended learning outcomes and the methods used to assess the extent to which they have been achieved" (European Centre for the Development of Vocational Training (CEDEFOP), 2011) is a main condition for developing good quality curricula.

To reach an alignment of the curriculum, Biggs (2014) has introduced a model called the constructive alignment model (CA). In his article "Constructive Alignment in University Teaching", Biggs presents a theoretical description of the constructive alignment design and then explains its practical operational method by focusing on a unit curriculum design. A step by step methodology is outlined to guide teachers and curriculum designers as to how to align a unit or course design.

Biggs defines constructive alignment (CA) as follows: "Constructive alignment is an outcome-based approach to teaching in which the learning outcomes that students are intended to achieve, are defined before teaching takes place". He adds that "Teaching and assessment methods are then designed to best achieve those outcomes and to assess the standard at which they have been achieved" (Biggs, 2014). Biggs also explains that his model is based on one of the major insights of the psychology of constructivism namely the idea that a learner constructs his/her own knowledge through actively engaging in the teaching/ learning activities (Biggs, 2014).

Within the expression "constructive alignment" the term constructive foregrounds the active role of the learner in the learning process: "the learner learns by doing". The term "alignment" underlines the role played by teachers in securing coherence between the stated learning outcomes of their courses, the teaching/ learning activities (TLAs) they design or select and the assessment tasks (ATs) which will enable them to, appropriately, measure the students' performance in alignment with the stated LOs. Alignment refers to the fact that in a good functional curriculum design, the ILOs, the TLAs and the ATs coherently converge towards the attainment of the learning outcomes. 
Even though the expression "constructive alignment" was first used by John Biggs, he traces the origin of its underlying principles to the 1950s in the USA and to Ralph (Tyler, 1949)and his idea that "learning takes place through the active behavior of the student" (Biggs, 2014).

Biggs (2014) also refers to Shuell (1986) who located the effective achievement of learning in the active engagement of learners in the learning activities. Shuell (1986) explains that "if students are to learn desired outcomes in a reasonably effective manner, then the teacher's fundamental task is to get students to engage in learning activities that are likely to result in their achieving those outcomes" (Shuell, 1986).

At the core of constructive alignment there is the idea that the assessment tasks (ATs), and the teaching/learning activities (TLAs) systematically support one another and converge towards the achievement of the intended learning outcomes with which they are aligned. In this context, Lebrun (2011) argues that constructive alignment amounts to pedagogical alignment and to the "coherence between the objectives, the evaluations and the methods" (Lebrun, 2011)4. Within the same line of thought, in her article "L'alignement Pédagogique: Un Concept Clé en Pédagogie Universitaire", Gérard (2015)argues that "constructive alignment (which she refers to as pedagogic alignment) is obtained when the learning objectives are coherent with the pedagogic activities and the evaluation strategies" (Gérard, 2015) .

To better explain the idea of alignment, Biggs gives the example of learning to drive where the intended learning outcome (ILO) is 'will be able to drive', the teaching/learning activity (TLA) is 'learning to drive through driving' and the assessment $\operatorname{task}(\mathrm{AT})$ is 'to demonstrate the ability to drive following the driving performance standards'. Biggs (2014) draws an analogy between learning following the constructive alignment method and learning to drive "In each case, the target act is at once the intended outcome, the method of teaching, and the means of assessing whether the desired criterion or standard of the outcome has been met" (Biggs, 2014).

The principle of coherence (which is the organizing principle of CA) requires that the ILOs, the ATs ${ }^{6}$ and the TLAs function as an integrated whole, i.e.as an aligned system. This systemic structural coherence requires, for its success, the alignment of the course or unit learning outcomes (CLOs) with the program learning outcomes (PLOs) and the alignment, within each course, of the ILOs with the ATs and the TLAs. A holistic vision of curriculum design implies that each component in the system interrelates with the other components and that the overall objective of the system is to support the achievement of the intended learning outcomes. In the case of a constructively aligned curriculum any mismatch between ILOs, ATs and TLAs results in gaps which undermine the good functioning of the system.

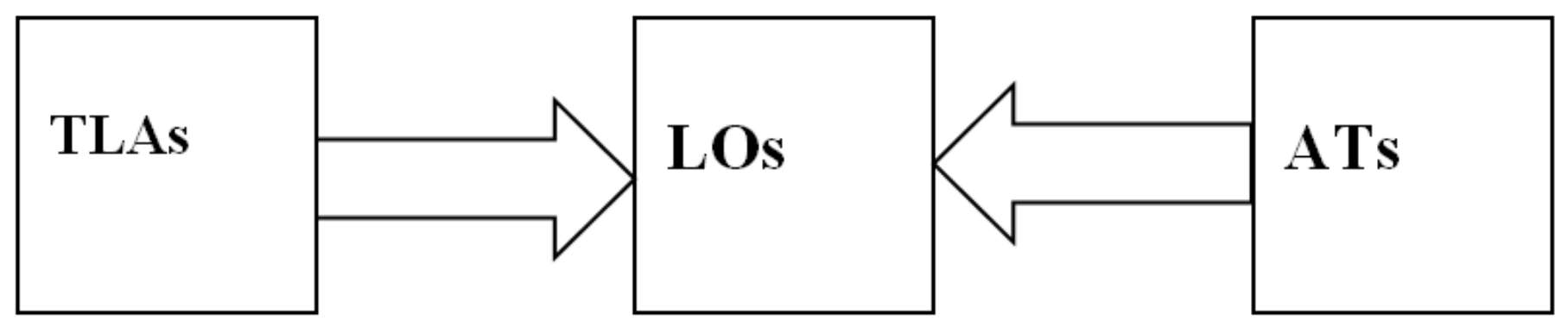

Figure-3. Constructive Alignment. Adapted from Biggs (1999)

Figure 3 illustrates the idea that the constructive alignment method starts from the intended learning outcomes and proceeds through aligning the ATs and the TLAs with the expected results stated in the ILOs. In the CA model, curriculum is designed following a holistic vision where all the components of the pedagogical situation function together as a whole to mutually support one another towards the achievement of the intended learning outcomes by students. The method used for this alignment is that of 'back design'.

\subsubsection{Back-Design}

The concept of 'back design' is a key concept and an important methodological tool in the constructive alignment design. The expression means exactly what it says: starting from the end i.e. the expected results, we design the necessary means (assessment tasks and teaching learning activities) to achieve that end. In more specific terms, we should first define and state the ILOs and, then, and only after we have a good idea of the results we want our students to reach, we proceed backwards and design the assessment tasks and which activities can best optimize the achievement of the intended learning outcomes.

At a more general level, 'back design' targets the relationship of coherence and alignment between a course learning outcomes (CLOs) and the program learning outcomes (PLOs). The CLOs are designed backwards, starting from the PLOs. In other words, for any training, the program learning outcomes are stated and then we proceed backwards to define the courses' learning outcomes in congruence and coherence with the program learning outcomes. Also, when stating any course learning outcomes, it is necessary to have a clear idea of the contribution brought by that course to the whole program. A course curriculum is always designed within the framework of a program and amid a network of other courses. A course curriculum designed separately from the program curriculum will necessarily be ineffective and will limit the students' chances for achieving the expected results. It is to be noticed that when we design a course curriculum, the following factors need to be taken into consideration:

- the contribution brought by that course to the program learning outcomes;

- the relationship between that course and the other courses at the same level and across levels;

${ }^{4}$ Translated from French by the writers of this study

${ }_{5}^{5}$ Translated from French

${ }^{6}$ Biggs revised the order of alignment from (TLAs) with (ILOs) first, to the alignment of the (ATs) with the (ILOs) first, and then the alignment of the (TLAs) follows. 
- the way that course builds on what precedes and prepares for what follows and converges towards the achievement of the learning outcomes.

\subsubsection{Backwash}

Backwash is another key concept in Biggs's constructive alignment. The basic idea is that students tend to learn only what will be assessed during tests and exams and this leads to rote learning and poor performance. Biggs asserts that "students learn what they think they will be tested on. This is backwash, when the assessment determines what and how students learn more than the curriculum does" (Biggs, 2003). Biggs suggests the use of backwash as a supportive factor for deep learning and for the optimization of students' performance.

According to Biggs, backwash can be the site of a substantial improvement of students' output if the assessment tasks "mirror" the curriculum. He explains: "you can't beat backwash, so join it. Students will always second-guess the assessment task and then learn what they think will meet those requirements. But if those assessment requirements mirror the curriculum, there is no problem. Students will be learning what they are supposed to be learning" (Biggs, 2003).

\subsubsection{The Operational Framework}

At the practical level, Biggs's constructive alignment model basically operates following three steps ${ }^{7}$ which could be schematized as shown in Figure 4.

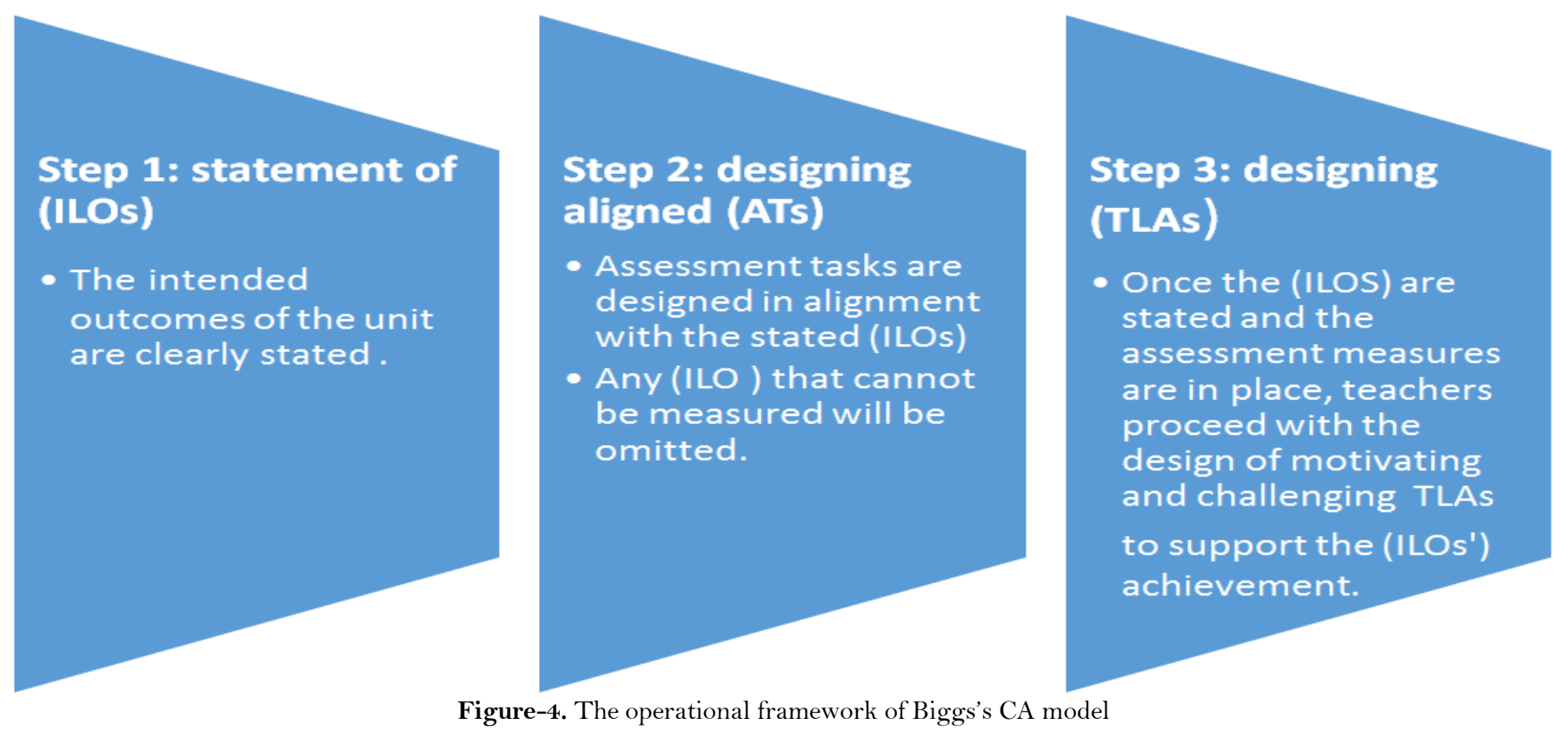

Step 1: LOs Statement. The literature on learning outcomes has dwelt, in detail, on the operational method for writing learning outcomes. Despite differences in the formulations, most studies agree that we should do the following when writing LOs:

- firstly, focus on the intended results;

- state four to six outcomes for each course;

- write clear and specific statements;

- number the LOs;

- start each outcome with the statement "upon completion of this course students will be able to (or any equivalent formulation to express this meaning);

- complete the above statement using an action verb which nominates a type of knowledge, a skill, or a competence which can be observed, measured and assessed at the end;

- avoid using verbs with ambiguous meanings or which describe actions that cannot be measured of the kind 'like', 'appreciate'...etc.

- make sure the LOs are realistically achievable within the set time limits;

- ensure that the LOs refer to a learning taxonomy and cover the cognitive, affective and psychomotor domains (when possible for the latter);

- think of stating LOs in relation to transversal and transferable skills;

- check the relevance of the LOs in relation to the course goals;

- ensure that the LOs bring a contribution to the program LOs;

(Maher, 2004; Adam, 2006; Kennedy et al., 2006; Warnier et al., 2010)

Biggs (2014) recommends for the statement of ILOs the use of only one or two verbs for each outcome and the recourse to a learning taxonomy like Bloom's taxonomy of educational objectives or Biggs SOLO taxonomy of levels of understanding. Biggs also argues for the necessity of contextualizing the LOs by reference to the national framework. (This will be taken into account later in the case study).

Step 2: Designing ATs. According to Biggs, the designed assessment tasks must be aligned with the stated ILOs. They should enable learners to demonstrate the achievement of the stated ILOs and teachers to measure the students' performance and evaluate its quality by reference to preset assessment criteria or rubrics.

'This study will not address the $4^{\text {th }}$ step "transform these judgments into final grades". (Biggs, Constructive Alignment in University Teaching) for two reasons: 1-It is a formal process of turning an already formed judgment into a grade; 2- To deal with grading rubrics and their technicalities requires a full study on its own. 
Step 3: Designing TLAs. Biggs (2014) explains that the design of an effective learning environment depends on "using teaching/learning activities (TLAs) that require students to engage each verb. In this way the activity nominated in the ILO is activated" (Biggs, 2014). It is this very process of activation that motivates students' active engagement in the learning activities. And, as the designed activities target the optimization of the ILOs, engaging with these TLAs will facilitate the achievement of the learning outcomes by students.

A simple example can clearly illustrate the three-step operation for the practical functioning of constructive alignment. If we refer to a course on 'Theories of Translation', the three steps can be aligned as shown in Figure 5.

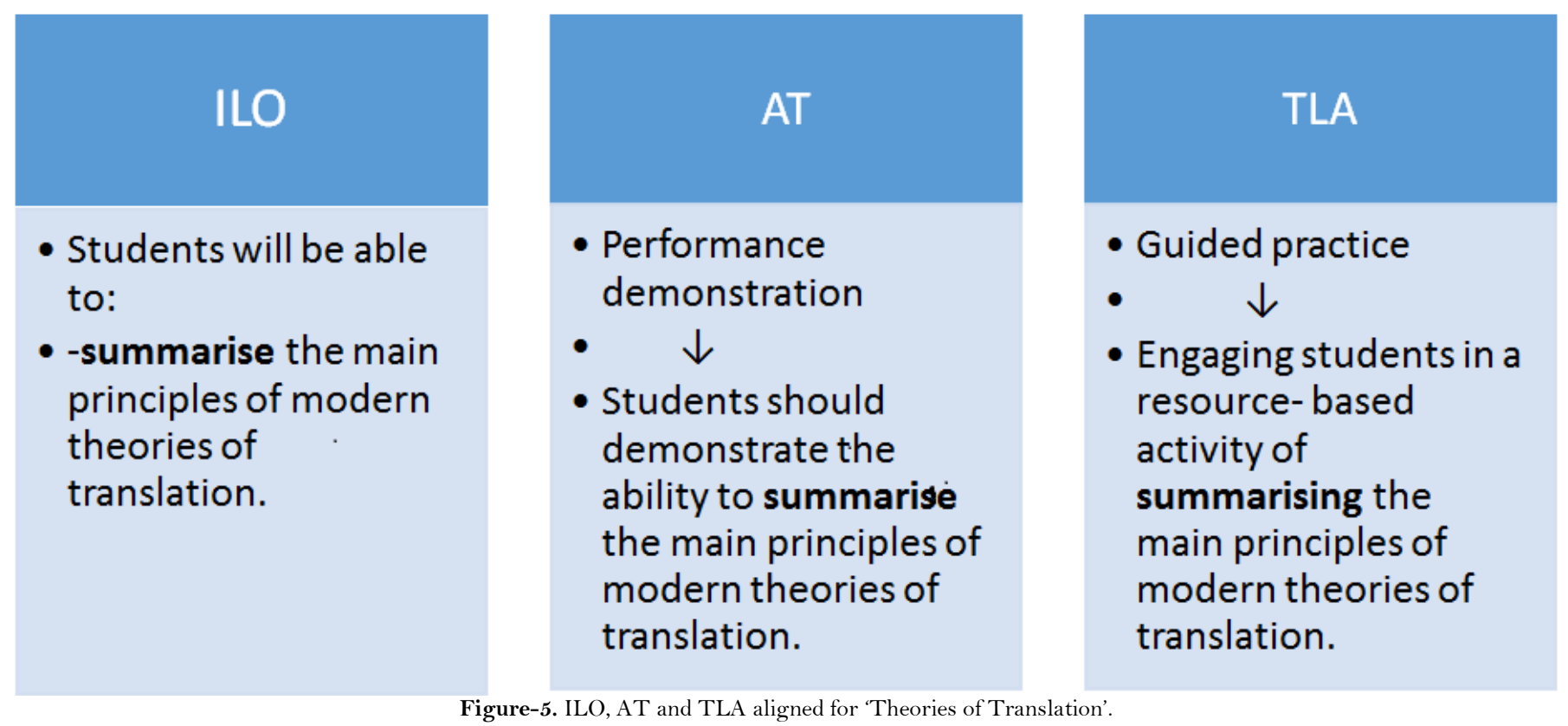

The verb 'to summarize' in the first column nominates the skill or ability targeted by the stated learning outcome. In the second column the verb 'to summarize' is used to demonstrate the performance of the nominated action and in the third column 'summarizing' activates the verb used in the stated learning outcome.

The presence of the same verb in each of the above columns is a 'marker' which indicates the good alignment between the intended learning outcome, the assessment task and the teaching/learning activity.

\section{Case Study: The Constructive Alignment of the Course 'Theories of Translation' 4.1. Preliminary Phase}

As mentioned earlier, the following case study is concerned with the course 'Theories of Translation', delivered by the department of English Language and Translation, Faculty of Arabic Language and Social Studies, Qassim University under the course code (ENG 271).

In 2014, two workshops were conducted by the researchers at the English department (female section) to identify mismatches in different courses.

The participants were thirty teachers from the department. The exercise had a two-fold purpose:

- $\quad$ awareness-raising of the importance of the LOs-based approach to curriculum design (workshop 1)

- performance- improvement in relation to curriculum alignment (workshop 2)

\subsubsection{Workshop 1}

The workshop proceeded through theoretical presentations and document analysis to explain the theoretical underpinning of the approach by reference to learning taxonomies and levels of understanding. Bloom's taxonomy of educational objectives and Biggs's SOLO taxonomy of levels of understanding, among others were discussed with the participants.

The NQF for HE in KSA (2009) was referred to and the importance allocated to the LOs-based approach in this document was highlighted.

The course specification (CS) template used by Qassim University was read and analyzed in the light of the learning taxonomies which inform its conception.

\subsubsection{Conclusions}

The awareness-raising session in relation to the LOs-based approach (workshop1) showed that:

- a large number of participants (around 70\%) had a very limited idea of the LOs-based approach, its theoretical underpinnings and its impact on deep learning;

- a very limited number of participants (around 10\%) had read the NQF document to understand the requirements of the LOs-based teaching/learning approach;

- a very few participants had already realized that the course specification template(CS) has been designed following Bloom's taxonomy in its original and revised versions;

Few participants had noticed that the NQF and the NCAAA (CS template) recommended (even required) the design of constructively aligned courses curricula following Biggs's mode 


\subsubsection{Workshop 2}

Workshop two was aimed at improving the teachers' practical performance in stating the intended learning outcomes effectively for their courses and then aligning the assessment tasks and the teaching/learning activities with the stated LOs.

The participants were divided into groups of four members who either delivered the same course or a course of the same field of specialization. The workshop proceeded through documentary analysis and followed two steps. First, a critical analysis of the course specifications used by the teachers was performed to identify existing mismatches then, a corrective re-statement of the LOs in some 'course specifications' and the alignment of some courses curricula were performed.

\subsubsection{Conclusions}

The analysis of the course specifications revealed the following:

- $\quad$ at times, a lack of precision, repetition, and overlap in the stated LOs;

- two main mismatches were identified in most course curriculum designs used in the department of English Language and Translation:

(1) A misalignment of the teaching/learning activities (TLAs) with the stated intended learning outcomes (ILOs): most course specifications indicated that the teaching method used was $100 \%$ traditional and this does not match with the student-centered approach which is at the heart of the LOs-based approach to teaching and learning or with the stated LOs.

(2) A mismatch between the assessment tasks (ATs) and the stated learning outcomes: in most course specifications, the exam schedule (mid-term and end of term exams) was used to fill in the column devoted to assessment tasks. Subsequently, during the academic year 2014/2015, training sessions were organized by Qassim University and the English department at the Faculty of Arabic Language and Social Studies. They were aimed at more awareness-raising and performance improvement and were targeted at the teachers. The training sessions focused on the theoretical scope of the LOs-based approach and on how course learning outcomes (CLOs) can be stated accordingly.

Following this action, the department started a program-wide revision which extended over several months and was organized through committees' and sub-committees work. The purpose was to revise and/or update the program curriculum (through revising the courses curricula) in alignment with the NQF. However, despite all the individual and institutional efforts, an important side was neglected and left out: the fact that the operational scope of the LOs-based approach to curriculum design is not limited to merely stating LOs. The approach, also, requires the design of assessment tasks and selection of learning/teaching activities in alignment with the stated LOs.

The following part of the case study aims to bring a contribution to this scope by focusing on the alignment of ATs and TLAs with the LOs. The reference to the course 'Theories of Translation' (ENG 271) is taken as an example which is by no means exclusive. Indeed, most courses in the department need to be constructively aligned.

\subsection{The Application of CA on the Course 'Theories of Translation' (ENG 271)}

The following part is an attempt to align the different components of the course "Theories of Translation". It aims at presenting a practical model of implementation of Biggs's theory of constructive alignment.

Step 1: LOs statement (by reference to the NQF for HE in KSA).

Under the heading "Domains of Learning Outcomes", the NQF (KSA) states four categories of learning expected from students. These are:

- knowledge, the ability to recall, understand and present information;

- cognitive skills;

- interpersonal skills and responsibility;

- communication, information technology and numerical skills;

- psychomotor skills (this fifth domain applies only in some program. (NQF, p. 4). The NQF mentions, among the conditions for successful learning, "the development of learning outcomes in different domains of learning" (NQF, p.10).

It is important to address the different learning domains and define LOs in relation to each one of them as follows:

Table-1. Learning Outcomes Statements for the Course "Theories of Translation"

\begin{tabular}{l|l}
\hline LO number & $\begin{array}{l}\text { LOs Statements } \\
\text { Upon completion of this course students will be able to: }\end{array}$ \\
\hline LO1 & summarize the main principles of the 'traditional' and modern theories of translation; \\
\hline LO2 & define the key concepts in the various theories of translation; \\
\hline LO3 & analyze the effects of 'traditional' and modern theories on methods of translation; \\
\hline LO4 & apply theories of translation in translating; \\
\hline LO6 & justify the use of a given theory in translating specific texts; \\
\hline
\end{tabular}

After we state the LOs (and still within the first step) we need to check if they cover the learning domains mentioned to this effect in the NQF. We can proceed as follows: 
Table-2. Checking the Relevance of LOs in Relation to Domains of Learning

\begin{tabular}{l|l|l|l|l}
\hline \multirow{2}{*}{ LOs } & \multicolumn{5}{c}{ Table-2. Checking the Relevance of LOs in Relation to Domains of Learning } \\
\cline { 2 - 5 } & Knowledge & Cognitive skills & $\begin{array}{l}\text { Interpersonal } \\
\text { skills } \\
\text { responsibility }\end{array}$ & $\begin{array}{l}\text { Communication and } \\
\text { information } \\
\text { technology skills }\end{array}$ \\
\hline LO1 & $\sqrt{ }$ & & \\
\hline LO2 & & & & \\
\hline LO3 & $\sqrt{ }$ & & & \\
\hline LO4 & & $\sqrt{ }$ & \\
\hline LO5 & & $\sqrt{ }$ & & $\sqrt{ }$ \\
\hline LO6 & & & & \\
\hline
\end{tabular}

The above demonstrates that the designed LOs cover the four domains of knowledge indicated in the (NQF) and this ensures the alignment of the stated LOs with the national frame of reference (NQF).

Step2: Aligning assessment tasks (ATs) with LOs.

Table-3. Alignment of Assessment Tasks with LOs

\begin{tabular}{|c|c|c|}
\hline LOs & Assessment tasks (ATs) & Assessment types \\
\hline $\begin{array}{l}\text { LO1: Summarize the main principles of 'traditional' } \\
\text { and modern theories of translation. }\end{array}$ & $\begin{array}{l}\text { Extended written-response task } \\
\text { Short written-response task } \\
\text { Response-selection task. } \\
\text { MCQ task. } \\
\text { Oral response task }\end{array}$ & $\begin{array}{l}\text { Formative } \\
\text { \&Summative }\end{array}$ \\
\hline $\begin{array}{l}\text { LO2: Define the key concepts in the various theories } \\
\text { of translation. }\end{array}$ & $\begin{array}{l}\text { Extended written-response task. } \\
\text { Short written-response task. } \\
\text { MCQ task. } \\
\text { Oral-response task. }\end{array}$ & $\begin{array}{l}\text { Formative } \\
\text { \&Summative }\end{array}$ \\
\hline $\begin{array}{l}\text { LO3: Analyze the effects of 'traditional' and modern } \\
\text { theories of translation on methods of translation. }\end{array}$ & $\begin{array}{l}\text { Reasoning proficiency task. } \\
\text { Practical performance task. } \\
\text { Extended written-response task. }\end{array}$ & $\begin{array}{l}\text { Formative } \\
\text { \&Summative }\end{array}$ \\
\hline LO4: Apply theories of translation to translating & $\begin{array}{l}\text { Practical performance task. } \\
\text { Reasoning proficiency task. }\end{array}$ & $\begin{array}{l}\text { Formative } \\
\text { \&Summative }\end{array}$ \\
\hline $\begin{array}{l}\text { LO6: Demonstrate the ability to participate actively } \\
\text { in "translation studies" group projects. }\end{array}$ & $\begin{array}{l}\text { Group- assessment task. } \\
\text { Peer-assessment task. } \\
\text { Tutor feedback. } \\
\text { Oral-performance assessment task. }\end{array}$ & $\begin{array}{l}\text { Formative } \\
\text { \&Summative }\end{array}$ \\
\hline
\end{tabular}

Step-3: Aligning LOs with TLAs.

Table-4. Aligning the LO statements (LOs) with Teaching / Learning Activities (TLAs)

\begin{tabular}{l|l|l}
\hline LOs & Targeted knowledge & Teaching/learning activities (TLAs) \\
\hline LO1 & Factual knowledge & $\begin{array}{l}\text { Lectures/ Resource-based guided individual work/Resource- } \\
\text { based guided group work/Self-regulated work/Free online- } \\
\text { reading/Guided in-class discussion. }\end{array}$ \\
\hline ELO2 & Conceptual knowledge & Same as above. \\
\hline LO3 & Cognitive skills & $\begin{array}{l}\text { Guided formative in-class practice/Supervised group } \\
\text { practice/Resource-based teacher controlled individual work/ } \\
\text { Teacher-supervised peer-activity. }\end{array}$ \\
\hline LO4 & Procedural knowledge & $\begin{array}{l}\text { Teacher-supervised individual work/Teacher-guided peer- } \\
\text { work/Teacher-supervised group work. }\end{array}$ \\
\hline LO5 & Cognitive skills & $\begin{array}{l}\text { Resource-based guided individual work/In-class guided formative } \\
\text { practice/ Peer-assessed formative practice/Group discussion. }\end{array}$ \\
\hline Adapted from Laudrillard, D., An Approach to Curriculum Design. wrwr.lkl.a.c.uk/Laudrillard-An Approach to Curriculum Design \\
practice with teacher and group formative feedback.
\end{tabular}

After we select the appropriate teaching and learning activities, it is good practice to ensure that the selected TLAs provide learning following different learning styles. The following matrix could be used as a means of checking the coherence of the TLAs with the learning methods. ${ }^{8}$ 
Table-5. Matrix to check the coherence of the TLAs with the learning methods

\begin{tabular}{|c|c|c|c|c|c|}
\hline TLAs & Assimilation & $\begin{array}{l}\text { Inquiry-based } \\
\text { learning (IBL) }\end{array}$ & Discussion & Experience & Production \\
\hline Lectures & $\sqrt{ }$ & & & & \\
\hline $\begin{array}{l}\text { Resource-based individual } \\
\text { work }\end{array}$ & & $\sqrt{ }$ & & $\sqrt{ }$ & $\sqrt{ }$ \\
\hline $\begin{array}{l}\text { Resource-based guided } \\
\text { peer work }\end{array}$ & & $\sqrt{ }$ & $\sqrt{ }$ & $\sqrt{ }$ & $\sqrt{ }$ \\
\hline $\begin{array}{l}\text { Resource-based guided } \\
\text { group work }\end{array}$ & & $\sqrt{ }$ & $\sqrt{ }$ & $\sqrt{ }$ & $\sqrt{ }$ \\
\hline Self-regulated work & & $\sqrt{ }$ & & $\sqrt{ }$ & $\sqrt{ }$ \\
\hline $\begin{array}{l}\text { Free on-line reading with } \\
\text { assigned tasks }\end{array}$ & & $\sqrt{ }$ & & $\sqrt{ }$ & \\
\hline Guided in-class discussion & & $\sqrt{ }$ & $\sqrt{ }$ & $\sqrt{ }$ & \\
\hline $\begin{array}{l}\text { In-class guided formative } \\
\text { practice }\end{array}$ & & & & $\sqrt{ }$ & $\sqrt{ }$ \\
\hline $\begin{array}{l}\text { Peer- assessed formative } \\
\text { practice }\end{array}$ & & $\sqrt{ }$ & $\sqrt{ }$ & & \\
\hline $\begin{array}{l}\text { Group-assessed formative } \\
\text { practice }\end{array}$ & & $\sqrt{ }$ & $\sqrt{ }$ & $\sqrt{ }$ & \\
\hline Oral presentation & & $\sqrt{ }$ & & $\sqrt{ }$ & $\sqrt{ }$ \\
\hline
\end{tabular}

It should be noticed that the TLAs which provide many learning opportunities and following different learning styles contribute more to the optimization of the chances for achieving the learning outcomes. The above table shows that the active methods are more effective in this context. The selection of TLAs which provide for different learning styles also ensures equity for all students.

At the end of the alignment process, a recapitulative table could be a good way of checking the degree of alignment of the designed course and whether it can be adopted or revised and improved. It should be remembered, as Biggs explains, that the nominated action stated in the LOs should be activated through the TLAs and demonstrated through the $A T s^{9}$ ("Constructive Alignment in University Teaching", p.4). To this effect, the verbs used can be good markers of alignment.

The following table presents one very simple example of how alignment can be checked ${ }^{10}$.

Table-6. An example of alignment of TLAs and ATs with course LOs

\begin{tabular}{|c|c|c|}
\hline $\begin{array}{l}\text { LOs } \\
\text { Upon completion of this course, students should be } \\
\text { able to: }\end{array}$ & $\begin{array}{l}\text { Examples of TLAs } \\
\text { Actively engaging students in: }\end{array}$ & $\begin{array}{l}\text { Examples of ATs } \\
\text { Performance demonstration tasks: }\end{array}$ \\
\hline $\begin{array}{l}\text { LO1: summarize the main principles of the } \\
\text { 'traditional' and modern theories of translation. }\end{array}$ & $\begin{array}{l}\text { Lectures on and surveys of the } \\
\text { theories of translation. Formative } \\
\text { summarizing: oral and written } \\
\text { practice (in and outside class). }\end{array}$ & $\begin{array}{l}\text { Sum up the main principles of the } \\
\text { 'traditional theories' of translation and } \\
\text { state their common points. }\end{array}$ \\
\hline $\begin{array}{l}\text { LO2: define the key concepts in the various } \\
\text { theories of translation. }\end{array}$ & $\begin{array}{l}\text { Resource-based concept defining } \\
\text { activity/peer readings to list key } \\
\text { concepts and define them. }\end{array}$ & $\begin{array}{l}\text { Define the concept of 'dynamic } \\
\text { equivalence' in the context of translation } \\
\text { reception. }\end{array}$ \\
\hline $\begin{array}{l}\text { LO3: analyse the effects of 'traditional' and modern } \\
\text { theories of translation on methods of translation. }\end{array}$ & $\begin{array}{l}\text { In-class formative analysis-practice. } \\
\text { Supervised analytical mini- research } \\
\text { projects. }\end{array}$ & $\begin{array}{l}\text { By reference to the socio-linguistic theory } \\
\text { of translation, analyze the effect of } \\
\text { semantic and formal adjustments on TL } \\
\text { texts. }\end{array}$ \\
\hline s of translation to translating. & $\begin{array}{l}\text { Applications of given theories to } \\
\text { translate specific types of texts. }\end{array}$ & $\begin{array}{l}\text { Translate this paragraph from Arabic into } \\
\text { English. Apply the socio-linguistic theory } \\
\text { of translation and mark in red the formal } \\
\text { adjustments you performed. }\end{array}$ \\
\hline $\begin{array}{l}\text { LO5: justify the use of a given theory in } \\
\text { translating specific texts. }\end{array}$ & $\begin{array}{l}\text { Engage students in discussions which } \\
\text { aim at justifying the use of specific } \\
\text { theories in samples of translated texts. } \\
\text { Formative practice to justify the } \\
\text { rationale behind the choice of a given } \\
\text { theory in translations by students }\end{array}$ & $\begin{array}{l}\text { Justify the use of the structural linguistic } \\
\text { theory of translation in machine } \\
\text { translating. }\end{array}$ \\
\hline $\begin{array}{l}\text { LO6: demonstrate the ability to participate actively } \\
\text { in 'translation studies' group projects. }\end{array}$ & $\begin{array}{l}\text { Engage students in collaborative } \\
\text { projects and ask them to demonstrate } \\
\text { interpersonal skills and leadership } \\
\text { abilities. }\end{array}$ & $\begin{array}{l}\text { Project presentation: demonstrate } \\
\text { collaborative work organization, the } \\
\text { ability to lead a group discussion and oral } \\
\text { fluency. }\end{array}$ \\
\hline
\end{tabular}

The reoccurrence of the same verbs (or any verbs with the same meaning) in the three columns is a good marker that the designed curriculum in the present case study is appropriately aligned and shows no mismatches.

\section{Conclusion}

This study has tackled the issue of the importance of the role played by curriculum design in supporting the achievement of the intended learning outcomes for students. It has argued for the necessity of having a holistic systemic vision of the learning experience within the frame of LOs-based approach. This research has shown that such a vision which is based on pedagogical coherence can materialize through the use John Biggs's constructive alignment model of curriculum design.

${ }^{9}$ Assessment tasks refer mainly to the ongoing formative assessment process and could be used for summative assessment as well.

${ }^{10}$ The examples of TLAs and ATs in the above table are not given as a model to be followed but as an illustration of how alignment functions on the whole. 
The basic tenets of Biggs's constructive alignment model (CA) were outlined in this study and the concepts of constructivism, alignment, back design, and backwash were highlighted as key concepts in this model. Within the context of LOs statements, the notions of embedded levels of reference and the importance of the use of a learning taxonomy have been emphasized. The necessity of stating intended learning outcomes which cover the different domains of knowledge has been underlined.

The operational framework provided in Biggs's constructive alignment model was presented in its three steps of LOs statement, the alignment of the assessment tasks (ATs) and then the alignment of the teaching/ learning activities (TLAs) with the intended learning outcomes (ILOs).

The case study has focused on the course 'Theories of Translation' delivered by the English Language and Translation department in the Faculty of Arabic Language and Social Studies, Qassim University under the course code (ENG271). The application of Biggs's constructive alignment model sought to align this course curriculum by putting to practice Biggs's notions of nominating the skill or ability to be acquired following the use of an action verb in the stated intended learning outcomes (ILOs). The notion of activation of the verb was used as the practical basis for aligning the teaching/learning activities (TLAs) and that of demonstrating the action was the guideline to align the assessment tasks (ATs).

With all its limitations, this research has been carried in the hope of increasing awareness as to the vital role played by good curriculum design in securing a successful passage of students from the expected results (ILOs) to the actual attainment of those results or (LOs) achievement. The second objective is to motivate teachers and curriculum designers to follow Biggs's model of constructive alignment to facilitate students' achievement of the intended learning outcomes.

\section{References}

Adam, S., 2006. An introduction to learning outcomes: EUA Bologna Handbook. European University Association, Article B2.3-1.Berlin: Raabe.

Biggs, J.B., 1996. Enhancing teaching through constructive alignment. Higher Education, 32(3): 347-364. View at Google Scholar | View at Publisher

Biggs, J.B., 1999. What the student does: Teaching for enhanced learning. Higher Education Research \& Development, $18(1): 1-19$.

Biggs, J.B., 2003. Teaching for quality learning at university. Buckingham: Open University Press.

Biggs, J.B., 2003a. Aligning teaching and assessment to curriculum objectives. Higher Education Academy. Retrieved from http://www.heacademy.ac.uk/sites/default/files/biggs-aligning-teaching-and-assessment.pdf.

Biggs, J.B., 2014. Constructive alignment in university teaching. HERDSA Review of Higher Education, 1. Retrieved from www.herdsa.org.au.

Biggs, J.B. and C. Tang, 2007. Teaching for quality learning at university. 3rd Edn., Maidenhead: McGraw Hill Education \& Open University Press.

Course Specification (C S), 2015. National commission for academic accreditation \& assessment. T6. Course Specifications. Retrieved from www.asbc.qu.edu.sa/Units/Adoption_quality/NCAAA/Documents/T6+Course+Specifications+English-version.pdf.

Dewalt, K.M. and B.R. Dewalt, 2002. Participant observation: A guide for fieldworkers. Walnut Greek, CA: AltraMira Press.

European Centre for the Development of Vocational Training (CEDEFOP), 2011. When defining learning outcomes in curricula, every learner matters. Briefing Note. Retrieved from www.cedefop.europa.eu/files/9060_en.pdf [Accessed April 2011 ].

European Commission Education and Culture DG, 2009. ECTS users' guide. Retrieved from ec.europa.eu/dgs/education_culture/repository/education/tools/docs/ects-guide_en.pdf.

Gaff, J.G. and J.L. Ratcliff, 1997. Handbook of the undergraduate curriculum - a comprehensive guide to purposes, structures, practices, and change. San Francisco: Jossey-Bass.

Gérard, L., 2015. L'alignement pédagogique: Un concept clé en pédagogie universitaire. Retrieved from cooperationuniversitaire.blogs.docteo.net/2015/08/25/lalignement-pedagogique-le-concept-cle-en-pedagogie-universitaire/.

Jackson, N., J. Wisdom and M. Shaw, 2003. Guide for busy academics: Using learning outcomes to design a course and assesslearning. Available from wings.buffalo.edu/ubtlc/resources/Course_design_for_busy_academics.pdf.

Kennedy, D., A. Hyland and N. Ryan, 2006. Writing and using learning outcomes: A practical guide. Retrieved from www.tcd.ie/teachinglearning/academic-development/assets/pdf/Kennedy_Writing_and_Using_Learning_Outcomes.pdf.

Lebrun, M., 2011. Les compétences et les "ccc" :Capacités, contenusetcontextes, learning outcomes, apprentissage et dispositif, approcheprogramme. Retrieved from http://lebrunremy.be/WordPress/?p=559.

Maher, A., 2004. Learning outcomes in higher education: Implicationsfor curriculum design and student learning. Journal of Hospitality, Leisure, Sport and Tourism Education, 3(2): 46-54. View at Google Scholar | View at Publisher

Mckimm, J., 2003. Curriculum design and development. Retrieved from www.faculty.londondeanery.ac.uk/e-learning/settinglearningobjectives/Curriculum_design_and_develpoment.pdf.

$\begin{array}{clllllll}\text { National } & \text { Qualifications } & \text { Framework } & \text { for } & \text { HE } & \text { in } & \text { KSA, } & \text { 2009. Retrieved }\end{array}$ http://www.mu.edu.sa/\%E2\%80\%A6/National\%20Framework\%20for\%20HE20inKSA.

Shuell, T.J., 1986. Cognitive conceptions of learning. Review of Educational Research, 56(4): 411-436. View at Google Scholar | View at Publisher

The Centre for Excellence in Teaching and Learning, 2012. Leading practices in curriculum. Web camosun ca cetl sites files leading practices in curriculum center for research on learning and teaching (CRLT), University of Michigan. Curriculum Design. Retrieved from www.crlt.umich.edu/assessment/curriculumdesign.

The University of Western Australia, n.d. Curriculum development. Retrieved from Curriculum development.file:///C:Users/user/Downloads /CI\%20General-Curriculum-Development\%20UWA.pdf.

Tyler, R.W., 1949. Basic principles of curriculum and instruction. Chicago: University of Chicago Press.

Warnier, P., L. Warnier and P. Parmentier, 2010. Et si on commençait par les résultats ? Elaboration d'unedémarche de définition des acquisd'apprentissage d'un programme de formation universitaire. Retrieved from http://alfresco.uclouvain.be/alfresco/service/guest/streamDownload/ffc3ffaa-9c7c-4cd 1-905c1f7781496d85/WarnierWarnierParmentier-AIPU-2010.pdf? guest=true.

Wiggins, G. and J. McTighe, 2001. Understanding by design. 2nd Edn., Alexandria, VA: Association for Supervision and Curriculum Development. 